\title{
ANTIBACTERIAL ACTIVITY OF FRACTIONS OF ETHYL ACETATE EXTRACT OF GARCINIA LATTISSIMA MIQ. FRUITS
}

\author{
NENENG SITI SILFI AMBARWATI ${ }^{1,2}$, AMARILA MALIK ${ }^{2 *}$, AGENG TRI LISTARI ${ }^{2}$, NIRWANA ${ }^{2}$, BERNA ELYA ${ }^{2}$, \\ MUHAMMAD HANAFI ${ }^{3}$
}

${ }^{1}$ Department of Family Well-Being, Faculty of Engineering, Universitas Negeri Jakarta, Jakarta, Indonesia. ${ }^{2}$ Department of Pharmacy, Faculty of Pharmacy, Universitas Indonesia, Depok, Indonesia. ${ }^{3}$ Research Centre for Chemistry, Indonesian Institute of Sciences (LIPI), Tangerang, Indonesia. Email: amarila.malik@ui.ac.id

Received: 20 April 2017, Revised and Accepted: 13 July 2017

\section{ABSTRACT}

Objectives: The emergence of new infections and increase in bacterial drug resistance has created a serious need for the expansion of new antibacterial agents from natural sources. The study was carried out to evaluate the antibacterial activity of fractions of ethyl acetate extract of Garcinia latissima Miq. fruits.

Methods: The fractionation was done using a silica gel column and organic solvents as the eluent, i.e., n-hexane, ethyl acetate, and methanol. All fractions were assayed for antibacterial activity, which was done by performing disc diffusion for growth inhibition against Bacillus subtilis and Pseudomonas aeruginosa. In addition, the growth inhibition activity was also examined by performing bioautography assay using pre-coated silica gel 60 GF 254 plates as the stationary phase. Fractions A-F were eluted using n-hexane:chloroform (1:4), while Fractions G-K were used ethyl acetate:dichloromethane (4:1) as the mobile phase. The plate was visualized by ultraviolet at $\lambda 254 \mathrm{~nm}$ and $366 \mathrm{~nm}$, while the other one was contacted with the inoculated agar medium to observe zone inhibition. Further, the minimum inhibitory concentration (MIC) value was determined by performing microdilution.

Results: The result showed that the antibacterial activity of all fractions was more active at inhibiting the growth of B. subtilis than P. aeruginosa, mainly for Fractions $\mathrm{H}$ and J. However, the strongest antibacterial activity was showed by Fractions $\mathrm{H}$ and J against B. subtilis, MIC $312.5 \mu \mathrm{g} / \mathrm{mL}$ (lower than reference, which is erythromycin antibiotic ( $25 \mu \mathrm{g} / \mathrm{mL})$, followed by Fraction D against B. subtilis MIC $625 \mu \mathrm{g} / \mathrm{mL}$, Fraction K against $P$. aeruginosa MIC $625 \mu \mathrm{g} / \mathrm{mL}$, whereas Fractions C, E, and G against B. subtilis, and Fraction E against P. aeruginosa also showed low MIC values (1.250 $\mu \mathrm{g} / \mathrm{mL})$.

Conclusions: The results indicated that fractions of G. latissima Miq. fruit ethyl acetate extracts possessed antibacterial activity. The most active fraction that inhibited the growth of $B$. subtilis was shown by Fractions $\mathrm{H}$ and J; these fractions have the potential to be developed as new antibacterial agents.

Keywords: Antibacterial activity, Garcinia latissima Miq., Fruit fraction, Bacillus subtilis, Pseudomonas aeruginosa.

C 2017 The Authors. Published by Innovare Academic Sciences Pvt Ltd. This is an open accessarticle under the CC BY license (http://creativecommons. org/licenses/by/4. 0/) DOI: http://dx.doi.org/10.22159/ajpcr.2017.v10s5.23104

\section{INTRODUCTION}

Infectious diseases have persisted as a major health problem for almost half a century now, and there has been increasing incidence of resistance to currently available antibacterials [1]. There is the need for intensive studies for the possible discovery of new agents with antibacterial potentials [1]. Microorganisms have unfavorable impact on the quality and safety of life [2]. To against these microorganisms widely used chemicals [2]. The occurrence of drug resistance demands new antimicrobial. Therefore, research need to be done to find new antimicrobials, especially from plants.

Since the existence of humans, plants have been used for the drug and a major source of phytochemicals existing in conventional medicine [3]. Ethnobotany studies have described the relationship of cultures and the traditional use of plants [3]. The chemical ingredients of plants play a major role in new cures. Antibiotics were a revolutionary development and way to control pathogens and infectious diseases. However, there are millions of people dependent on these synthetic drugs. Citizens who live in remote places rely on traditional medicines with which they are familiar and trust [4]. About three-quarters of the world's population relies primarily on plants and plant concentrates for their health care [4]. The presence of various constituents of phytochemicals in plant tissue that influence a definite physiological action on the human body caused drug plants have a large role in the discovery of new drugs. Very few of these chemicals are toxic also [4]. The plant Garcinia latissima Miq. is part of the Clusiaceae (Clan, garcinia) family, which consists of 27 genera, about 1,090 species [5]. Many are xanthones [5]. G. latissima Miq. has a broad spectrum of medicinal properties, such as anti-Bacillus subtilis and anti-Staphylococcus aureus [6].

We conducted prior research on the antimicrobial activity of $G$. latissima fruit ethyl acetate extracts against two positive bacteria ( $S$. aureus and B. subtilis), two negative bacteria (Escherichia coli and Pseudomonas aeruginosa), and two fungi (Trichophyton mentagrophytes and Candida albicans). Our results showed that this extract was active against $B$. subtilis and $P$. aeruginosa and inactive against other bacteria. The purpose of this study was to evaluate the antibacterial activity of the fractions of G. latissima fruits ethyl acetate extracts against $B$. subtilis and $P$. aeruginosa.

\section{METHODS}

\section{Extract material}

G. latissima Miq. fruit ethyl acetate extract from our previous research in the Phytochemistry Laboratory, Faculty of Pharmacy, Universitas Indonesia was used.

\section{Preparation of fractions}

We fractioned a portion of the extract of $G$. latissima Miq. fruits $(25 \mathrm{~g}$ ) by filter column chromatography over $250 \mathrm{~g}$ of silica gel 60 (S). The 
column chromatography was eluted with approximately $2.5 \mathrm{~L}$ of the solvents hexane, ethyl acetate, and methanol, in order of increasing polarity, until a clear extract was obtained at the end of the elution [3]. We collected the eluate in $100-\mathrm{mL}$ bottles and subjected each fraction to evaporate. Fractions were stored at $4^{\circ} \mathrm{C}$ until assayed.

\section{Antimicrobial assay of different fractions \\ Bacterial strains}

We individually tested the various fractions of G. latissima Miq. fruit ethyl acetate extract against two bacteria including Gram-positive bacteria (B. subtilis ATCC 6633) and Gram-negative bacteria (P. aeruginosa ATCC 27853).

We obtained the pure bacterial strains from the Microbiology Laboratory of Pharmacy Faculty, Universitas Indonesia. B. subtilis was cultured overnight (for $24 \mathrm{hrs}$ ) at $37^{\circ} \mathrm{C}$ in nutrient agar (Merck/Difco). P. aeruginosa was cultured overnight in Cetrimide (Merck). The bacteria colonies were transferred into a sterile loop or cotton swab and mixed well from the fresh agar plate (Diastuti et al., 2014). The suspension was adjusted to achieve a turbidity equivalent to a 0.5 McFarland turbidity standard (Diastuti et al., 2014). This suspension resulted in a suspension containing approximately $1 \times 10^{9} \mathrm{CFU} / \mathrm{mL}$ [7]

\section{Antibacterial test using the agar diffusion method (disc) and diameter of the inhibition zone}

A preliminary evaluation of the antibacterial activity of the different fractions of the G. latissima Miq. ethyl acetate extracts was determined using the disc diffusion method [4]. Briefly, all the samples were dissolved in dimethyl sulfoxide (DMSO) [3]. We impregnated the disc ( $6 \mathrm{~mm}$ in diameter) with $5,000 \mathrm{mg} / \mathrm{mL}$ fractions $(20 \mu \mathrm{L} /$ disc) placed on the inoculated agar. $1 \mathrm{~mL}$ of inoculum of the bacterial strains $\left(10^{6}\right.$ $\mathrm{CFU} / \mathrm{mL}$ ) was added to $4 \mathrm{~mL} 11$ antibiotic medium (Merck). Then, the vortex was used to obtain a homogenous seed layer. The seed layer immediately was poured into Petri dishes $(90 \mathrm{~mm})$ already filled with $20 \mathrm{~mL}$ of the solid base layer (nutrient agar [Difco]) for B. subtilis and Cetrimide for $P$. aeruginosa). Then, $6 \mathrm{~mm}$ wells were used and filled with $20 \mu \mathrm{L}$ of samples $(20,000 \mathrm{ppm})$. The positive reference for bacteria used erythromycin (15 $\mu \mathrm{g} / \mathrm{disc})$ (Oxoid) and gentamycin $(10 \mu \mathrm{g} / \mathrm{disc})$ (Oxoid). The negative control used DMSO. $3 \mathrm{hrs}$ were required for pre-incubated the Petri dishes at room temperature, allowing the complete diffusion of the samples; then, they were incubated at $37^{\circ} \mathrm{C}$ for $24 \mathrm{hrs}$ [3]. The total diffusion of samples into the nutrient agar was visually perceptible and confirmed.

\section{Minimum inhibitory concentration (MIC)}

The MIC of plant fractions was evaluated by the microdilution method [2]. The fraction solutions were transferred in $80 \%$ DMSO, v/v $(20,000 \mathrm{ppm}, 50 \mu \mathrm{L})$ into 96 well plates in the first row. Then, $50 \mu \mathrm{L}$ of nutrient broth was added to all test wells. Seven-fold serial dilutions were performed using a micropipette such that each well had $50 \mu \mathrm{L}$ of the test material in serially descending concentrations. Finally, $50 \mu \mathrm{L}$ of bacterial suspension ( $10 \mu \mathrm{L}$ of assay bacterial inoculum of approx. $10^{6} \mathrm{CFU} / \mathrm{mL}$ and $40 \mu \mathrm{L}$ nutrient broth) was added to each well. The fraction solution concentrations were 5,000, 2,500, 1,250, 625, 312.5, 156.25 , and $78.125 \mathrm{ppm}$ from top to bottom. Each plate had a set of controls: A column with a broad-spectrum antibiotic as a positive control, and a column with $100 \%$ DMSO (v/v) solution as a negative control. The plates were prepared in triplicate and incubated at $37^{\circ} \mathrm{C}$ for $24 \mathrm{hrs}$, respectively. Then, $10 \mu \mathrm{L}$ of MTT salt solution was added to each well (BBI Life Sciences) prepared by dissolving $6 \mathrm{mg}$ of MTT in $10 \mathrm{~mL}$ of sterile distilled water. Visual assessment was done to see whether there was any discoloration. Their growth was marked by color changes from yellow or colorless-to-purple or pink. The lowest concentration in which no color change appeared was taken as the MIC value [4].

\section{Bio-autography}

In 1946, Goodall and Levi combined the paper chromatography method with contact bioautography to detect different penicillins for their determination. After that, Fischer and Lautner introduced thin-layer chromatography (TLC) in the same field. This technique combines TLC with both biological and chemical detection methods. Several works have been done on the screening of organic extracts, mainly plant extracts, for antibacterial activity by TLC-bioautography.

This research used the agar diffusion technique or contact bioautography [8]. In addition, known as the agar contact method, it is the least-employed one of the techniques. It involves the transfer by diffusion of the antibacterial agent from the chromatogram (TLC) to an agar plate previously inoculated with the microorganism tested. After $1 \mathrm{hr}$ to allow diffusion, the chromatogram is removed, and the agar plate is incubated. The growth inhibition zones appear in the place where the antibacterial compounds come into contact with the agar layer [8].

Silica gel TLC 60 GF 254 plates were used. Plant extracts $(200 \mathrm{mg} / \mathrm{mL})$ were applied $(5 \mu \mathrm{L})$. The chromatogram was developed using n-hexane:chloroform (1:4) for Fractions C-F and ethyl acetate:dichloromethane $(4: 1)$ for Fractions G-K as the solvent. TLC plates were eluted in duplicate, and one set was used as the reference chromatogram. Chromatograms were visualized by ultraviolet irradiation ( 254 and $366 \mathrm{~nm}$ ) and vanillin/sulphuric acid 2\% spray reagent. The other sets were used for bioautography [9].

Bioautography was performed with $B$. subtilis and P. aeruginosa exhibiting high sensitivity to the fractions. For bioautography, the solvent of the TLC plates was completely removed. TLC plates were placed face down on agar containing an aliquot of an overnight culture and incubated at $37^{\circ} \mathrm{C}[10]$.

\section{RESULTS AND DISCUSSION}

The antibacterial activity of fractions of ethyl acetate extract of G. latissima Miq. fruits against B. subtilis and P. aeruginosa was determined. To perform a rapid screening study of potential antibacterial activity, a disc diffusion assay followed by bioautography is the best combined method, in addition to MIC [3]. The inhibition zone results are presented in Table 1.

The disc diffusion assay results showed that fractions of G. latissima Miq. fruit ethyl acetate extract exhibited strong growth inhibition activity against $B$. subtilis with diameter, i.e., $12.283 \pm 2.2420 \mathrm{~mm}$ and $11.108 \pm 0.3800 \mathrm{~mm}$ by Fractions $\mathrm{E}$ and D, respectively. Strong activity against $P$. aeruginosa was exhibited as well, but by Fraction $\mathrm{K}$ only with an inhibition zone diameter of $16.100 \pm 7.6254 \mathrm{~mm}$.

According to previous study, fractions with an inhibition zone diameter over $11 \mathrm{~mm}$ are assumed to have strong antimicrobial activity; while $6-11 \mathrm{~mm}$ and $<6 \mathrm{~mm}$ are categorized as moderate and weak, respectively [11]. The antibiotic used in this study was carried out as

Table 1: Zone of inhibition of G. latissima Miq. fruit ethyl acetate extract fractions

\begin{tabular}{lll}
\hline \multirow{2}{*}{ Fractions } & \multicolumn{2}{c}{ Diameter of inhibition zone $(\mathbf{m m})^{\mathbf{b}}$} \\
\cline { 2 - 3 } & B. subtilis & P. aeruginosa \\
\hline A & 0 & 0 \\
B & 0 & 0 \\
C & $9.458 \pm 1.5239$ & 0 \\
D & $11.108 \pm 0.3800$ & 0 \\
E & $12.283 \pm 2.2420$ & $9.316 \pm 5.4862$ \\
F & $10.392 \pm 1.4489$ & $8.242 \pm 0.4706$ \\
G & $9.992 \pm 0.3412$ & $10.583 \pm 0.591$ \\
H & $9.135 \pm 0.7134$ & $9.408 \pm 0.4620$ \\
I & 0 & $8.542 \pm 0.1242$ \\
J & $6.725 \pm 0.8239$ & $8.692 \pm 0.8351$ \\
K & 0 & $16.100 \pm 7.6254$ \\
Antibiotic standard & $23.58 \pm 0.988$ & $17.92 \pm 0.549$ \\
\hline
\end{tabular}

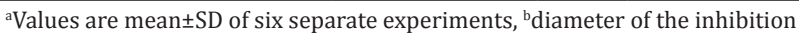
zone $(\mathrm{mm})$ includes the disc diameter $(6 \mathrm{~mm})$. P. aeruginosa: Pseudomonas aeruginosa, B. subtilis: Bacillus subtilis, G. latissima: Garcinia latissima 
a positive control for the assay performed. There is no consensus on the acceptable level of inhibition for natural products when compared with antibiotics standards [12]. Hence, the antibacterial potential of the fractions can be assume as good, indeed, although the zone diameters obtained are much lower than results of antibiotics. The Gram-positive bacteria (e.g., B. subtilis) are known to be more sensitive to plant active extracts than Gram-negative bacteria (e.g., P. aeruginosa). This finding, as suggested by Ohadoma et al., indicates that the sensitivity to each group of bacteria is based on the fact that the cell wall of Gram-positive bacteria is less complex than other groups and does not have the effect of the natural sieve against large molecules [2]. The results for the MIC are presented in Table 2 .

The results of the MIC assay showed that fractions of $G$. latissima Miq. ethyl acetate extract indicated moderate activity against $B$. subtilis with the lowest MIC values (312.5 ppm by Fractions $\mathrm{H}$ and J). The fractions of $G$. latissima Miq. ethyl acetate extract showed weak activity against $P$. aeruginosa with the lowest MIC values ( 625 ppm by Fraction K). Fernandez et al. reported that the strength of antibacterial activity can be categorized using MIC values. Fractions that showed values of MIC at concentrations of $<100 \mathrm{ppm}$ were classified as having good antibacterial activity [13]. Values of MIC from 100 to $500 \mathrm{ppm}$ and from 500 to $1,000 \mathrm{ppm}$ were classified as moderate and weak, respectively, while those over $1,000 \mathrm{ppm}$ were considered inactive [13]. In general, the antibacterial activity of the tested fractions in this study was set to be comparable with the reference antimicrobe erythromycin against B. subtilis and gentamycin against $P$. aeruginosa.

The results indicated that fractions of ethyl acetate showed moderate inhibition activity against $B$. subtilis and weak inhibition activity against $P$. aeruginosa. The fractions showed varying degree of inhibitory effects. The results revealed that the most susceptible bacterial strain was B. subtilis to Fractions $\mathrm{H}$ and J. Medicinal plants are an effective source of both traditional and modern medicines [14]. Herbal medicine has been shown to have real utility, and about $80 \%$ of the rural population depends on it for primary healthcare [14]. The evaluation of the antibacterial potentials of various plants is imperative, as infections are known to be caused by microorganisms, especially genitourinary infections [14]. The MIC tests result of different fractions showed that $B$. subtilis more vulnerable than $P$. aeruginosa. The plant fractions were more efficient against Gram-positive than Gram-negative organisms [14]. The MIC of the plant's fractions for Gram-negative organisms was $>1,000 \mu \mathrm{g} / \mathrm{mL}$, except Fraction K with a value 625 ppm.

Tetrazolium salt used in this MIC microdilution assay is a (3-(4,5-dimethylthiazol-2-yl)-2,5-diphenyltetrazolium bromide), which is converted to purple formazan by the dehydrogenases enzyme of living microorganisms [15]. This reaction is a reduction reaction, and the purple to show the bacteria growth [15]. Makes this assay reliable for visual observation. The bioautography results show that the growth of the bacteria tested, B. subtilis, was inhibited by a higher number of inhibition bands, indicating a higher number of active compounds compared to P. aeruginosa (Figs. 1 and 2). Some of the compounds, which were separated by TLC previously, showed that they could act against both bacteria. The compounds that have activity against $B$. subtilis and $P$. aeruginosa may possess broad antibacterial action; they may even be general metabolic toxins that could be toxic to animals as well [16]. Bioautography is an antibacterial activity test that is not quantitative. This test showed that the fractions of TLC could separate into some compounds, which have antibacterial activity. The absence of bioactivity in some fractions of fruit ethyl acetate extracts allow for synergistic and additive interactions so that they are active [16].

Humanity urgently needs new antibiotics to fight bacterial diseases. Many antibiotics are known to be powerful, but no longer effective against these and other infections. The situation is mostly related to increasing bacterial resistance to commonly used antibiotics [15]. Chromatography is the perfect tool for analyzing plant constituents. The chromatographic method that is ideal for this type of connection
Table 2: MIC values of ethyl acetate fraction extracts of G. latissima Miq. fruits against B. subtilis and P. aeroginosa (ppm)

\begin{tabular}{lll}
\hline Fractions & B. subtilis & P. aeruginosa \\
\hline A & $>5,000$ & $>5,000$ \\
B & $>5,000$ & $>5,000$ \\
C & 1,250 & $>5,000$ \\
D & 625 & $>5,000$ \\
E & 1,250 & 1,250 \\
F & 2,500 & $>5,000$ \\
G & 1,250 & 5,000 \\
H & 312.5 & 2,500 \\
I & $>5,000$ & 2,500 \\
J & 312.5 & 2,500 \\
K & $>5,000$ & 625 \\
Antibiotic standard & 25 & 0.39 \\
\hline
\end{tabular}

P. aeruginosa: Pseudomonas aeruginosa, B. subtilis: Bacillus subtilis, G. latissima: Garcinia latissima

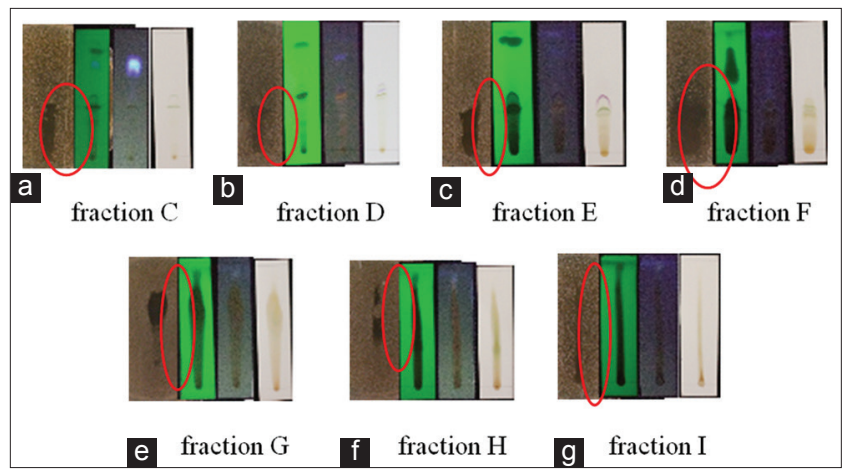

Fig. 1: (a-g) Thin-layer chromatography Si60 F254 plates - contact (indirect) bioautography of fractions of Garcinia latissima Miq. ethyl acetate extract against Bacillus subtilis

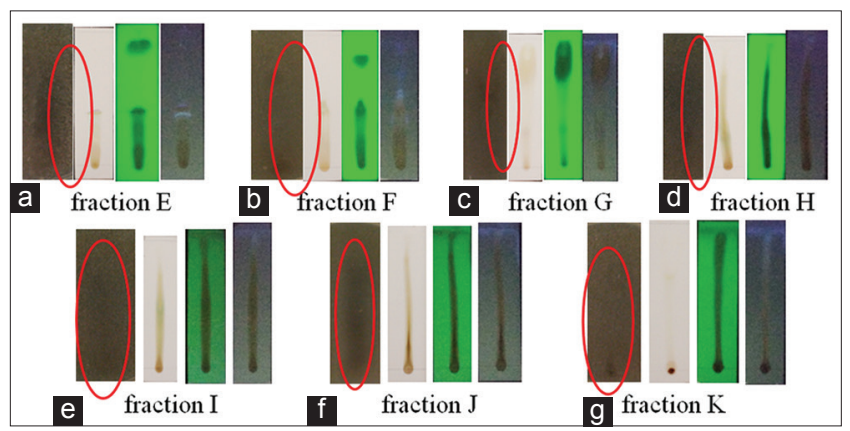

Fig. 2: (a-g) Thin-layer chromatography Si60 F254 plates - contact (indirect) bioautography of fractions of Garcinia latissima Miq. ethyl acetate extract against Pseudomonas aeruginosa

is thin-layer chromatography (TLC). TLC-bioautography (TLC-B) is a combination of TLC with biological assay such as antibacterial. Thinlayer chromatography-contact bioautography (TLC-CB) is one of three variants of a TLC-B method (the others are direct and agar overlay bioautography), a method of separation was performed using TLC, then tested the activity, and observed visually after incubation. The antibacterial activity could be attributed to the effects of bioactive phytochemical constituents, such as flavonoids [1].

\section{CONCLUSION}

This study demonstrated that fractions of ethyl acetate extract of G. latissima Miq. fruits possessed various degrees of antibacterial activity. It is concluded that ethyl acetate fractions of G. latissima Miq. 
fruits possessed moderately antibacterial activity. Therefore, this could serve as a potential source of industrial drugs useful in some bacterial infections. To obtain the active ingredients of $G$. latissima Miq. fruit fractions, we need further research to isolate the active compound and will likely need to synthesize the active compounds as well.

\section{REFERENCES}

1. Okoye TC, Akah PA, Ezike AC, Mbaoji FN. Antimicrobial and antispasmodic activity of leaf extract and fractions of Stachytarpheta cayennensis. Asian Pac J Trop Med 2010;3(3):189-2.

2. Ohadoma SC, Nnatuanya I, Amazu LU, Okolo CE. Antimicrobial activity of the leaf extract and fractions of lupinus arboreus. J Med Plant Res 2014;8(8):386-91.

3. Martins S, Amorim EL, Sobrinho TJ, Saraiva AM, Pisciottano MN, Aguilar CN, et al. Antibacterial activity of crude methanolic extract and fractions obtained from Larrea tridentata leaves. Ind Crops Prod 2013;41:306-11.

4. Zubair M, Rizwan K, Rasool N, Ahmed V. Antimicrobial potential of various extract and fractions of leaves of Solanum nigrum. Int $\mathrm{J}$ Phytomed 2011;3(1):63-7.

5. Stevens PF. The families and genera of fascular plants. In Flowering Plants. Berlin: Royal Botanic Gardens, Kew; 2007. p. 48-66.

6. Rao KS. Antibacterial activity of some medicinal plants of papua new guinea. Int J Pharm 1996;34(3):223-5.

7. Syah YM, Juliawaty LD, Singgih M. Antibacterial curcuma xanthorrhiza extract and fractions. J Math Fundam Sci 2014;46(3):224-34.
8. Balouiri M, Sadiki M, Ibnsouda SK. Methods for in vitro evaluating antimicrobial activity: A review. J Pharm Anal 2016;6(2):71-9.

9. Sanches NR, Cortez DA, Schiavini MS, Nakamura CV, Filho BP. An evaluation of antibacterial activities of Psidium guajava (L.). Braz Arch Biol Technol 2005;48(3):429-36.

10. Kumar GS, Jayveera KN, Kumar CK, Swamy BM, Umachigi P, Kumar DV. Antibacterial screening of selected Indian medicinal plants against acne-inducing bacteria. Pharmacol Online 2007;47:34-7.

11. Nurcahyanti AD, Dewi L, Timotius KH. Antioxidant and antibacterial activities from polar and non polar basil (Ocimum sanctum Linn.) seed extracts. J Teknologi dan Industri Pangan 2011;XXII(1):1-6

12. Waltrich KK, Hoscheid J, Prochnau IS. Antimicrobial activity of crude extracts and fractions of Vernonia polyanthes less. Rev Bras Med Campinas 2015;17 4 Suppl II:909-14

13. Fernandes MR, Dias AL, Carvalho RR, Souza CR, Oliveira WP. Antioxidant and antimicrobial activities of Psidium guajava L. spray dried extracts. Ind Crops Prod 2014;60:39-44.

14. Nwidu LL, Nwafor PA, Vilegas W. Antimicrobial activity of Carpolobia lutea extracts and fractions. Afr J Tradit Complement Altern Med 2012;9(3):323-8

15. Choma I, Jesionek W. TLC-Direct Bioautography as a high throughput method for detection of antimicrobials in plants. Chromatography 2015;2(2):225-38

16. Suleiman MM, McGaw LJ, Naidoo V, Eloff JN. Detection of antimicrobial compounds by bioautography of different extracts of leaves of selected South African tree species. Afr J Tradit Complement Altern Med 2010;7(1):64-78 